\title{
WestVirginiaUniversity
}

THE RESEARCH REPOSITORY @ WVU

Graduate Theses, Dissertations, and Problem Reports

2018

\section{Homage To Cube}

\section{Ken Lu}

Follow this and additional works at: https://researchrepository.wvu.edu/etd

\section{Recommended Citation}

Lu, Ken, "Homage To Cube" (2018). Graduate Theses, Dissertations, and Problem Reports. 7210. https://researchrepository.wvu.edu/etd/7210

This Thesis is protected by copyright and/or related rights. It has been brought to you by the The Research Repository @ WVU with permission from the rights-holder(s). You are free to use this Thesis in any way that is permitted by the copyright and related rights legislation that applies to your use. For other uses you must obtain permission from the rights-holder(s) directly, unless additional rights are indicated by a Creative Commons license in the record and/ or on the work itself. This Thesis has been accepted for inclusion in WVU Graduate Theses, Dissertations, and Problem Reports collection by an authorized administrator of The Research Repository @ WVU. For more information, please contact researchrepository@mail.wvu.edu. 
HOMAGE TO CUBE

\author{
Ken Lu \\ Thesis submitted \\ to the College of Creative Arts \\ at West Virginia University \\ in partial fulfillment of the requirements for the degree of \\ Masters of Fine Arts in \\ Ceramics
}

Robert Moore, M.F.A., chair

Shoji Satake, M.F.A.

Zhang Naijun, M.F.A.

Joseph Galbreath, M.F.A.

Dylan Collins, M.F.A.

School of Art and Design

Morgantown, West Virginia

2018

Keywords: Ceramics, Installation, Minimalism, Geometric Abstraction, Systemic Art, Cube, Cognitive Dissonance, Mental Chaos, Subjectivity 


\section{Abstract \\ HOMAGE TO CUBE}

Ken Lu

My MFA written thesis addresses work completed and shown in a thesis exhibition, Homage to Cube (2018), at West Virginia University (2015 - 2018) as well as significant influences on my studio process. This thesis, along with the supporting exhibition, address my research on my driving forces for my work, A sub-category of Minimalism called Systemic Art, while adhering to my artistic practice and philosophy. The exhibition is an installation consisting of 625 individual ceramic cubes displayed in accordance to a two-dimensional cube template to create a sanctuary. The installation acts as a mental escape for the audience and myself from current chaos and subjectivity by providing a sanctuary for contemplation. 


\section{Acknowledgments}

I would like to express my special appreciation and thanks to my advising committee, Shoji Satake, Robert Moore, Joseph Galbreath, Zhang Naijun, and Dylan Collins; you all have been extremely influential in my artistic and conceptual development. Special thank you to Prof. Shoji Satake, for your many years of guidance, education, both academically and personally, and giving me a chance to further my studies in the United States. To Prof. Olson, thank you for your encouragement, guidance, and support of my work. Danny and Peggy Lu, thank you for bringing me up and being my parents, words will never be enough to express how blessed I am to have both of you. Last, but not least, to Liao Qi Mei for being at my side through the three years of my MFA pursuit in the United States. 


\section{Table of Contents}

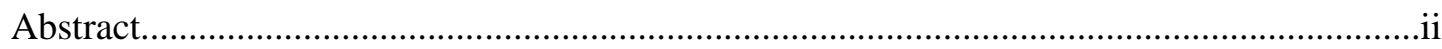

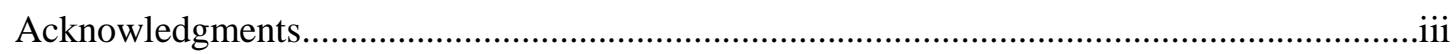

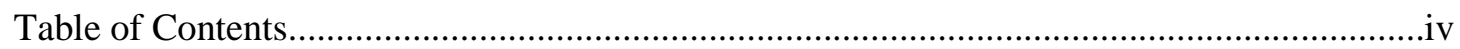

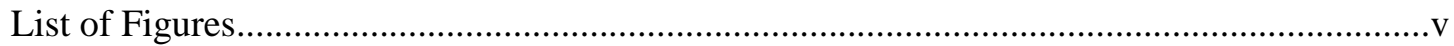

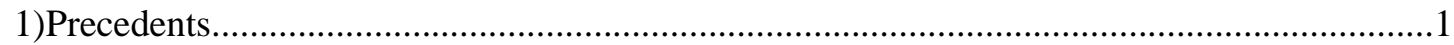

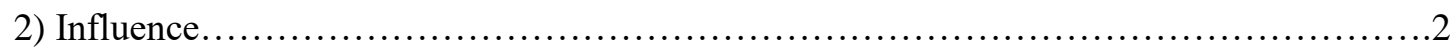

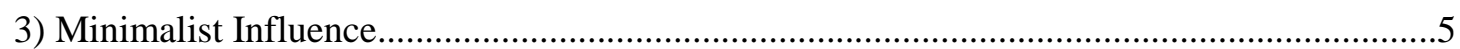

4) The Cube

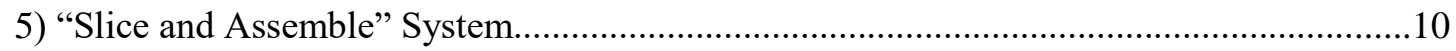

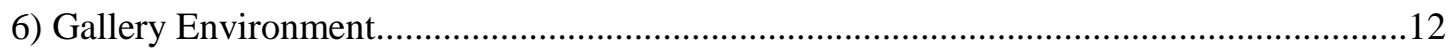

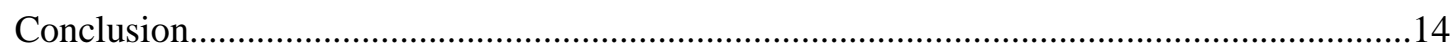

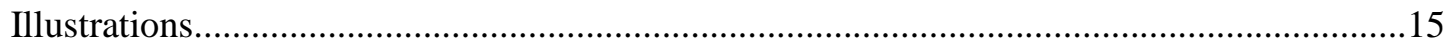

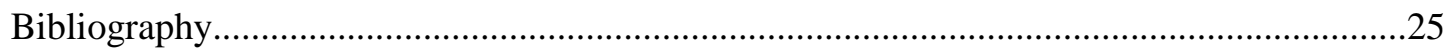

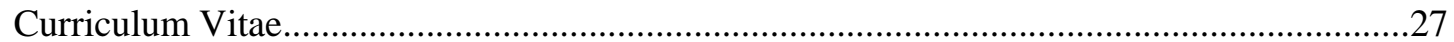




\section{List of Figures}

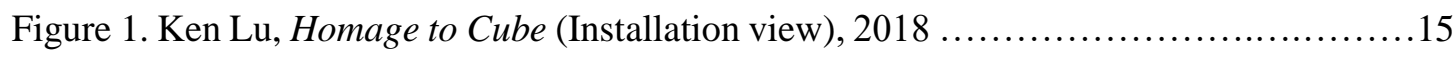

Figure 2. Ken Lu, Title, Stainless Steel Table, Overview of Installation, 2018_................15

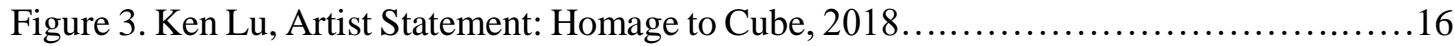

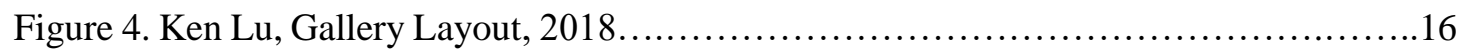

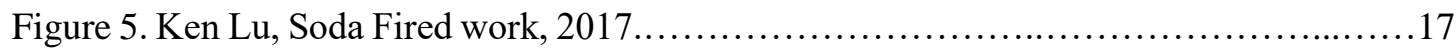

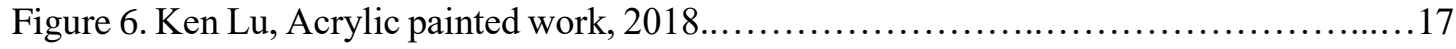

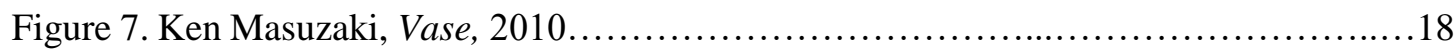

Figure 8. Ken Mihara, Untitled, 2007................................................ 18

Figure 9. John Mason, Folded Cross, Yellow-Gold, 2002...................................19

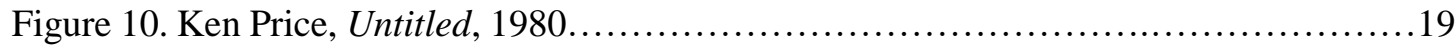

Figure 11. Kenneth and Mary Martin, Rotation Multiple Not Limited, 1968..................20

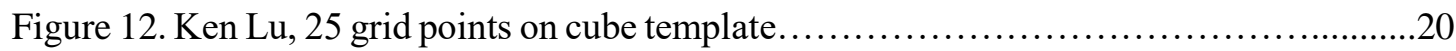

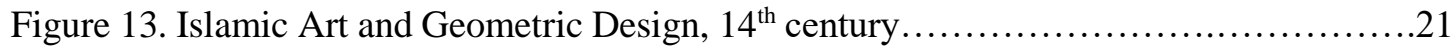

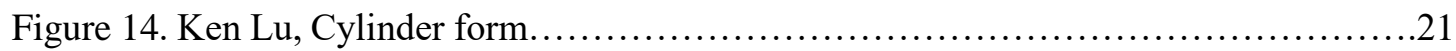

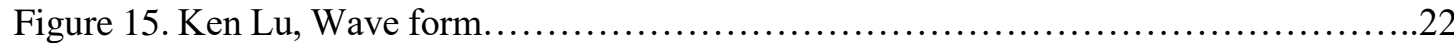

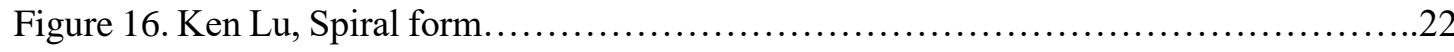

Figure 17. Ken Lu, Arch form........................................................23

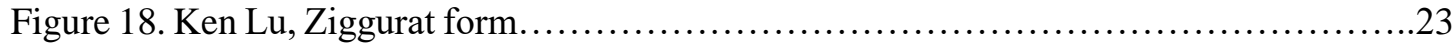

Figure 19. Ken Lu, Height increment...................................................24

Figure 20. Peter Eisenman, Memorial to the Murdered Jews of Europe, 2005................24 


\section{Precedents}

Homage to Cube (2018) (fig. 1) is my MFA thesis exhibition that was exhibited in Laura Mesaros Gallery in West Virginia University between the March 19 - 23, 2018. The gallery vestibule consists of title, stainless steel table displaying twenty-five sliced and assembled cubes; overview of installation (fig. 2), artist statement (fig. 3), and a layout of the installation (fig. 4). Homage to Cube is an installation comprising of 25 pedestals in a 5 x 5 grid system with an increment of 1 foot for each column. Each pedestal adheres to a thirty-five-inch interval from all four sides. The various heights of the pedestals differ between forty-eight to twenty-four inches which creates a slope to the top left-hand corner of the gallery. Each sculpture is made up of twenty-five individual cubes which is glued together to create different forms. 


\section{Influence}

Being labelled as a Generation Y millennial (1981-1999), ${ }^{1}$ the biggest shaping event that my generation has been exposed to is the explosion of the internet and social media. In my childhood, technology was in its infant stage where desktop computers were present in homes while all cellphones had number pads to them. While studying for my BFA in China, the notion of using social media applications such as Facebook, Instagram, Twitter, and Snapchat were starting to gain momentum but with China's internet firewall, such platforms were inaccessible. Since my arrival in United States of America for my Master's degree, I became aware of cognitive influences and the side effects of social media on a personal level.

Surfing through Facebook daily, the US politics, presidential elections, gun violence, Dakota Access Pipleline, \#MeToo movement, LGBTQ movement, Black Lives Matter, Teacher strikes, xenophobia or Islamophobia, international/national geographical conflicts, nuclear threats, patriotism, and many other alarming issues recur constantly on news feed without a breather. The sudden and constant bombardment of global information is mentally overwhelming for me to wrap my head around especially looking from a third person perspective. There were way more layers than just a simple news feed on Facebook.

\footnotetext{
${ }^{1}$ Ruth N. Bolton, A. Parasuraman, Ankie Hoefnagels, Nanne Migchels, Sertan Kabadayi, Thorsten Gruber, Yuliya Komarova Loureiro, David Solnet, "Understanding Generation Y and their use of social media: a review and research agenda", Journal of Service Management, Vol. 24 Issue: 3 (2013), pp.245, https://doi.org/10.1108/09564231311326987
} 
There seems to be a trend in every new stream of happenings. A mass shooting, Trump's ridiculous political move, Teacher's strikes, Syria's use of chemical weapons, catches the public's attention, then an endless discussion from panelists, experts, politicians, news presenters starts a massive dialog or argument about the issue for a whole week across different telecommunication avenues. Then suddenly, nothing, and they move on to the next news flash. Inevitably, the continuous stream of polar viewpoints burdens and torments my emotions. It seemingly endless wave of peevish blows from different directions creates cognitive dissonance. I call it 'mental chaos'.

Besides the 'mental chaos' caused by the overflow of information, people are ostentatious about their opinions through daily conversation and through social media. Subjectivity, which is based on and influenced by one's taste and opinion, is more prominent in the United States due to the primacy of Individualism² where one's opinion matters more instead of collectivism, which is commonly found in Asian countries. An individual's judgments and perspective are further amplified through social media platforms which inevitably become emotional stimuli for stress and anxiety on me. Since coming to the US, I am constantly in a state of skepticism about everything, from items in my news feed, healthcare, politics, food labels to people's opinions. There are always varying outlooks from everyone on every issue; the more I listen, the harder it is to decipher what is true or the truth.

This sense of mental chaos and subjectivity are the two major driving forces for my thesis exhibition, Homage to Cube, revering the absolute cube as it allows me to be in a state

\footnotetext{
2 Ruoyu Duan, "Individualism in America.” Faculty of English Language and Culture Guangdong University of Foreign Studies. November 2014.
} 
of tranquility. By minimalizing elemental components to just form, system, and bare clay color, Homage to Cube is my way of order and clarity from the mental chaos and subjectivity. 


\section{Minimalist Influence}

"Now the whole of everyday political, social, historical, economic reality is incorporated into the simulative dimension of hyper-realism." ${ }^{3}$-Jean Baudrillard

New machines for communication and information ranging from cellphones to the web, are a significant and affective register on the production of subjectivity. ${ }^{4}$ In this technological era, people are capable of freely conveying their opinions and feelings through different modes of communication. Homage to Cube creates a repulsion towards the chaos of social media with simplicity, purity, and repetition. In a way, it acts as a mental sanctuary for myself and hopefully the audience to be aware of physical presence in the gallery space. My animosity for subjectivity has directed me to research Minimalism and Geometric Abstraction as my major influences for Homage to Cube.

The simplest definition of Minimalism (1960s - 1970s) is a style distinguished by severity of means, clarity of form, and simplicity of structure and texture. ${ }^{5}$ Minimal artists such as Donald Judd (1928-1994), Sol LeWitt (1928-2007), Carl Andre (b. 1935), Robert Morris (b. 1931), Agnes Martin (1912-2004), and Dan Flavin (1933-1996) primarily used geometric forms in modes of singularity or repetition in their artwork. ${ }^{6}$ The removal of any

3 Charles Harrison, and Paul Wood. Art in Theory, 1900-2000: An Anthology of Changing Ideas, 2nd Ed. ed. Malden, MA: Blackwell Pub, 2003, pp 1019

${ }^{4}$ Pierre-Felix Guattari, The Guattari Reader, ed. Gary Genosko (Blackwell Publishers. 1996), 194

5 Edward Strickland, Minimalism: Origins, (Bloomington: Indiana University Press, 1993), 4

6 James Sampson Meyer, Minimalism, (London: Phaidon, 2000), 15 
emotional, intuitive decision making, or any affinity to anything beyond its literal presence ${ }^{7}$ was the main goal of Minimalism. Art critic Barbara Rose stated, "The most obvious common denominator was how empty everything was, how much effort went just into rejecting all but the very barest, irreducible minimum." ${ }^{8}$

In my work, I embrace the same minimalistic approach of removing aesthetic choices or emotional stimuli, hence, not imposing ideas or intentions on my audience. The cube is a common denominator of any man-made building block. It is an absolute unit with neutrality and detachment from real world objects. Using a cube as my starting form and implementing a "slice and assemble" system with a two-dimensional cube template as the grid is a way of giving order and clarity to the chaos of current issues.

Systematic artists make a conscious choice to let an artwork be dictated by a system. By doing so, they intentionally remove of artistic choices even though the outcome is not desired which also resists subjectivity. Systematic artist Peter Lowe commented on implementing a system as, "A way(system) of communicating an intelligent idea in terms of shapes, colors and forms. An organizational principle that I predetermine to see what the outcome would be." With most artwork, the artist envisions what the piece would convey and work towards it through experimentation and implication of technical skills. The outcome becomes the goal of art making. By administering a system, there is no attachment to the outcome.

\footnotetext{
7 ibid., 15

8 Edward Strickland, Minimalism: Origins, (Bloomington: Indiana University Press, 1993), 8

9 Peter Lowe, Edward Grabczewski, The Systems Art of Peter Lowe (2008), Video, 48.31, Sep 2013, https://www.youtube.com/watch?v=oOJw4WpUbE8\&t=1437s
} 
Besides the dichotomy between industrial and handcrafted objects, working in a clay medium is crucial in combating mental chaos and stress. Clay itself as a material is formless. It takes the form of the artist's intention and records the artist's actions. Thus, clay as a medium is also neutral. Physically manipulating every one of the individual 625 pieces in Homage to Cube out of clay puts me in a state of tranquility and equanimity. I thoroughly enjoy working with the tactile and malleable quality of clay. Working in this medium is a cognitive escape for me from the 'mental chaos'.

Through my MFA journey, I have experimented with various ways of decoration and colors on cube-derived forms such as soda firing (fig. 5) and acrylic paint (fig. 6) but asking myself, does it have to be decorated or glazed? Decoration seems to add more burden to my work. Stripping it down to just the natural color of ceramics in a way resents stimulating colors which we are constantly exposed. I came to terms of appreciating my work solemnly for its formal aesthetic.

In accordance with Minimal Art, my work, Homage to Cube, focuses on three elements: geometric shape (the cube), a two-step "slice and assemble" system using a grid, and bare natural ceramic color. These elements will be described and analyzed in the next few sections. 


\section{Cube}

I have always been inspired by the dichotomy of geometry and clay. Both elements have polar properties; clay is commonly associated with organic elements while geometry is acquainted with hard edge line quality. The technical challenge of achieving sharp edges and smooth surfaces in ceramics which mostly are handcrafted has always intrigued me. Unlike other materials where machinery is used to obtain such qualities. Works of Ken Matsuzaki (fig. 7), Ken Mihara (fig. 8), John Mason (fig. 9) and Ken Price (fig. 10) are contemporary artists who I am inspired by and represent this same dichotomy in my work.

The cube, also known as a special cuboid or hexahedron, is made of three pairs of parallel lines intersecting at 90-degree angles, which creates eight vertices, 12 edges, and six equilateral surfaces. Naturally occurring cube forms can only be found in pyrite, sugar and salt grains, and wombat's turd. As pyrite is not found in most households and while no one is viewing sugar and salt at a micro-level, the cube form is not commonly seen in the human environment. The cube is also the common denominator for any man-made design. With this said, the denominator refers to the absolute unit and thus, the cube transcends everything to the point of being independent and objective. Therefore, the cube has neutrality in the form and emotional detachment.

I am inspired by Plato's ideology of an absolute geometric form in a different dimension. In "Theory of Forms," (400 - 300 BCE) Plato considered geometry and numbers as the most 
reduced and essential and therefore the ideal, philosophical language. ${ }^{10}$ Geometry and mathematics are a universal language that transcends nationality, and race. This allows my audience from different kinds of backgrounds to enjoy the sculptures for what they are.

Homage to Cube is a study of different ways of dissecting a cube and joining it back to yield different forms according to the rules that I implemented. The study of a geometric form holds the perfect and paradigmatic truth ${ }^{11}$ which is my solution towards cognitive dissonance and mental chaos. It allows me to detach myself from the present realm and enter a meditative state of mind to keep my sanity.

${ }^{10}$ Robert Lawlor, Sacred Geometry: Philosophy and Practice, (Thames \& Hudson, 1982), 6

${ }^{11}$ Piers Bursill-Hall, "Why do we study geometry? Answers through the ages." DPMMS Centre for Mathematical Sciences Wilberforce Road, Cambridge (2002): 3 


\section{"Slice and Assemble" System}

Kenneth Martin (1905-1984), Mary Martin (1907-1969) (fig. 11), and Sol LeWitt all used a mode of system through grids, permutations, Fibonacci series, or the Golden section to art creation. Incomplete open cubes (1974) by Sol LeWitt consist of a collection of 122 frame structures. Each structure is the lattice of a cube with edges removed yet the structure remains connected three-dimensionally. ${ }^{12}$ LeWitt started off by sketching hexagons, which are the three-dimensional representation of a cube. Akin to my work, I plot out the grid points on which the sliced portion will be assembled (fig. 12). This gives me control and exhibits unity and order.

The use of geometric shapes in a system can be predominately seen in Islamic Art and Geometric Design (fig. 13) as a form of decoration for textiles, ceramics, metalwork, architectural elements, and manuscripts. ${ }^{13}$ With the use of basic instruments such as a compass and ruler, the Arabs constructed geometric design patterns made up of simple shapes, namely square, pentagon, and hexagon. These elements are combined, rearranged, duplicated to form a regular tessellation that is infinitely expandable. The purpose of using

\footnotetext{
${ }_{12}$ Michael Reb, Analysis of Variation of Incomplete Open Cubes by Sol LeWitt, Kansas State University, 2013, 3

${ }^{13}$ Islamic Art and Geometric Design, The Metropolitan Museum of Art, New York, 2004, Accessed: April 4, 2018, https://www.metmuseum.org/ /media/Files/Learn/For\%20Educators/Publications\%20for\%20Educator s/Islamic_Art_and_Geometric_Design.pdf
} 
geometric shapes in Islamic Art and Geometric Design was to stress the importance of unity, logic, and order which are the very same values I am aiming for in my sculptures.

Homage to Cube is an installation containing only three-point cross sectioned cubes.

There are two limiting factors to the way each cube is sliced:

1. Each sliced cross section surface is symmetrical.

2. Increments of one centimeter along one edge or two edges.

With limitations set, there are 63 different ways of slicing a cube. Due to the limited gallery space, I could only exhibit only three-point cross section. there are twenty-five different sets of three-point cross sections in a 5 x 5 grid. In each set, the sliced portion is assembled back to the parent portion on an untouched equilateral surface consisting of twenty-five grid points on a two-dimensional cube template. This equals a total of 625 variations.

In each set of twenty-five cubes, I use an epoxy glue to attach the cubes to create cylinders (fig. 14), waves (fig. 15), spiral (fig. 16), and arches (fig. 17). Each set differs by angle variations, ziggurat pattern (fig. 18), or slight increments in height (fig. 19). I want my audience to appreciate these minimalistic sculptures for their formal qualities and slight deviations with the aid of arrangement of varying height pedestals. 


\section{Gallery Environment}

The layout of the gallery of those twenty-five pedestals plays a crucial role to Homage to Cube. My intention was to create a sanctuary for my audience to contemplate and take a moment from daily routine to appreciate these minimalistic forms for that they are.

Memorial to the Murdered Jews of Europe (2005) (fig. 20) by Peter Eisenman was a major inspiration to the idea behind the gallery layout of pedestals. Memorials are places for homage to significant being or event, a site for contemplation of past mistakes or revere. That is what Peter Eisenman had in mind when he architected Memorial to the Murdered Jews of Europe which consist of 2,711 rectangular concrete slabs, also known as stele, are placed on a sloping stretch of land with identical lengths and widths, but varying heights. ${ }^{14}$ Each stele is meticulously placed at intervals of thirty-nine inches from any four directions. With similar layout to my setup of my installation, I too placed my pedestals at intervals of thirty-five inches from any four directions. This is a critical element which heightens the awareness of one's surroundings and attention to physical space in the gallery environment allowing my audience to be mentally present in physical space. On an average, art viewers spend a median time of 17 seconds on any artwork in a museum ${ }^{15}$. With the strategic placement of my pedestals, my aim to increase the amount of time for viewers to spend looking at my artwork and notice the minute changes between each adjacent individual cube.

\footnotetext{
14 Jackie Craven, “About the 2005 Berlin Holocaust Memorial” last modified March 24, 2018, https://www.thoughtco.com/the-berlin-holocaust-memorial-by-peter-eisenman-177928

15 Isaac Kaplan, "How Long Do People Really Spend Looking at Art in Museums?”, Last modified November 7, 2017, https://www.artsy.net/article/artsy-editorial-long-people-spend-art-museums
} 
There are various pedestal heights ranging from 48, 42, 36, 30, and 24 inches. Nine 48 inches pedestals are placed at the outermost perimeter and the pedestal height gradually converge to the top left-hand corner pedestal of 24 inches. There are two objectives to this orientation, allowing full view of all twenty-five sculptures and different point of view of each sculpture.

The definitive arrangement of pedestals in Homage to Cube heightens viewer's mental awareness of physical environment due to the slight constrain of walkway space and ultimately being present in the installation. This reaches my purpose for viewers to spend time among the sanctuary of cubic sculptures and appreciating the forms for what they are. 


\section{Conclusion}

My MFA thesis exhibition, Homage to Cube, is a milestone of my experience in the USA. It provides a sanctuary for my audience to take a break from their hectic daily routine to experience a tranquil site without the burden from artist subjectivity. There is no message I am trying to convey to my audience besides simply enjoying my journey of formal exploration of cubes with my made up "slice and assemble" system. The process of constructing each individual cube has provided me an avenue for meditation and hopefully, letting my audience be immerse in the sanctuary of cubes, appreciating the simplicity of form, rhythm, order, system, and natural clay body color of Homage to Cube. 


\section{Illustrations}

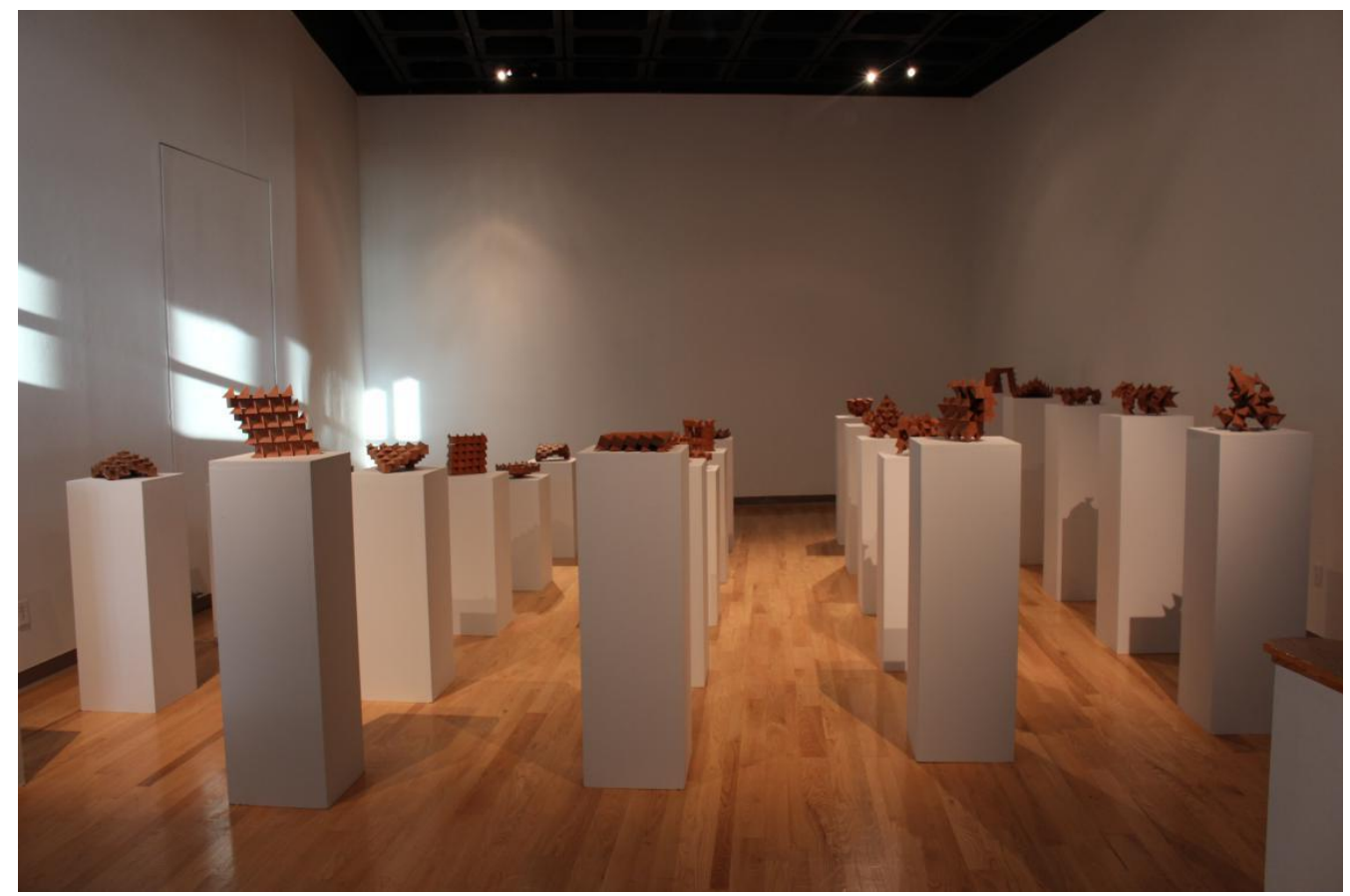

Fig. 1. Ken Lu, Homage to Cube, 2018. (Photo Courtesy of Liao Qi Mei).

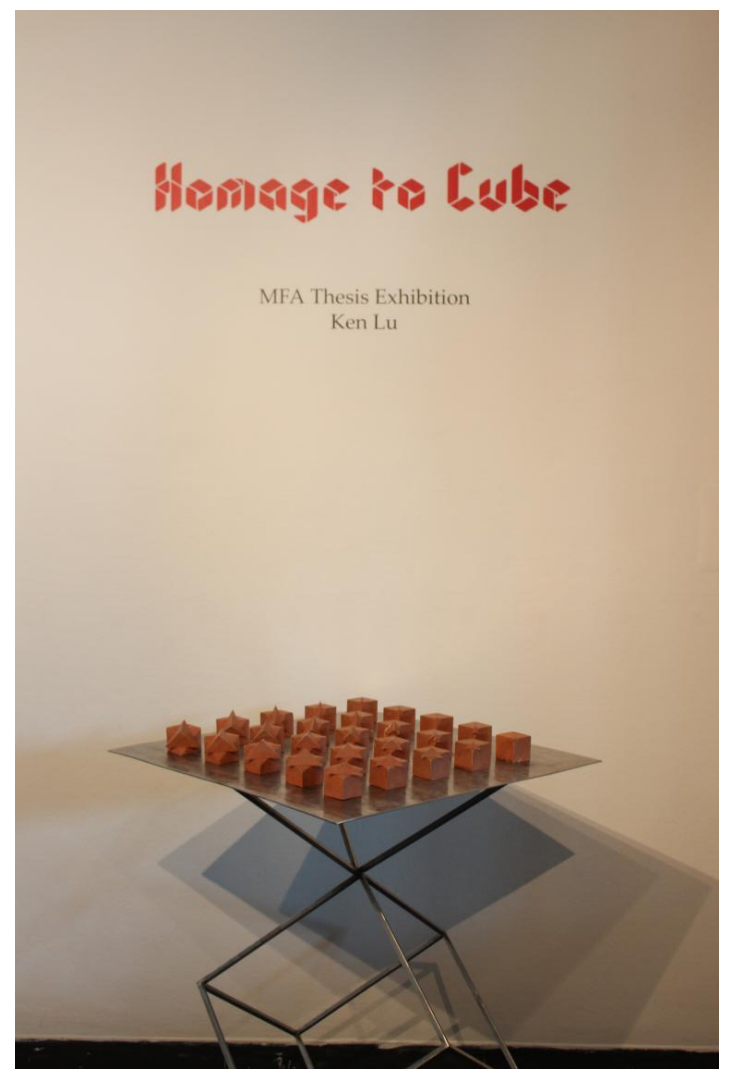

Fig. 2. Ken Lu, Title, Stainless Steel Table, Overview of Installation, 2018. (Photo Courtesy of Liao Qi Mei). 
Artist statement: Homage to Cube

Homage to Cube is a formal exploration of slicing and assembling a cube. The formal language of my work exhibits subtlety and reservedness. Using a non-objective, neutral, and basic form; the cube, as my starting point.

The cube, also known as a special cuboid, to me is one of the fundamental building blocks of design. As a common denominator, it possesses neutrality and independence. The cube is constructed by 3 parallel sets of lines intersecting at 90 degrees angles creating a 8 edges, 12 vertexes, and 6 surfaces. By implementing the cube through a two step "Slice and Assemble" system on a one centimetre interval grid, I am able to create 625 different forms.

Clay as a medium is unassuming and characterless, but at the same time, working with clay is therapeutic and equanimous. Clay itself is formless and neutral, it is through the hand of an artist that it is shaped and molded. Physically handcrafting every individual cube allows me to be in a tranquil state of mind, a way of escaping the 'chaos' by focusing on the job at hand.

In this installation, I want my audience to take a silent moment away from their daily routine to enjoy these minimalistic forms for what they are. Physically immerse yourself in "Homage to Cube" to engage each sculpture from different entrance points, through three basic elements of form, system, and scale of the work.

Fig. 3. Ken Lu, Artist Statement, 2018. (Photo Courtesy of Ken Lu).

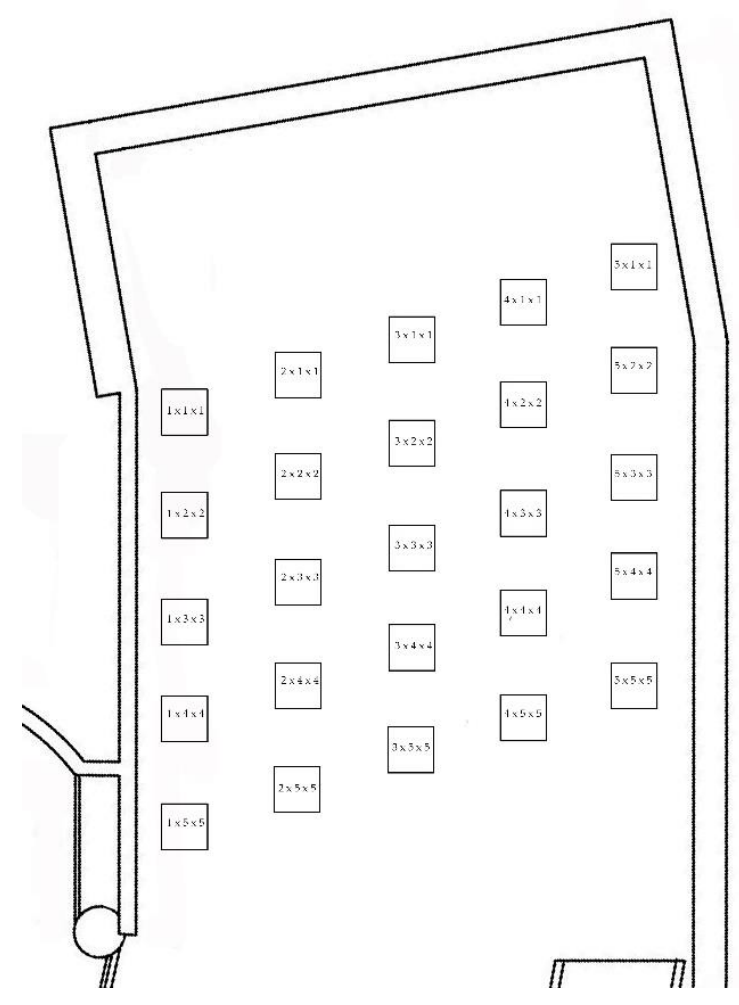

Fig. 4. Ken Lu, Gallery Layout, 2018. (Photo Courtesy of Ken Lu). 


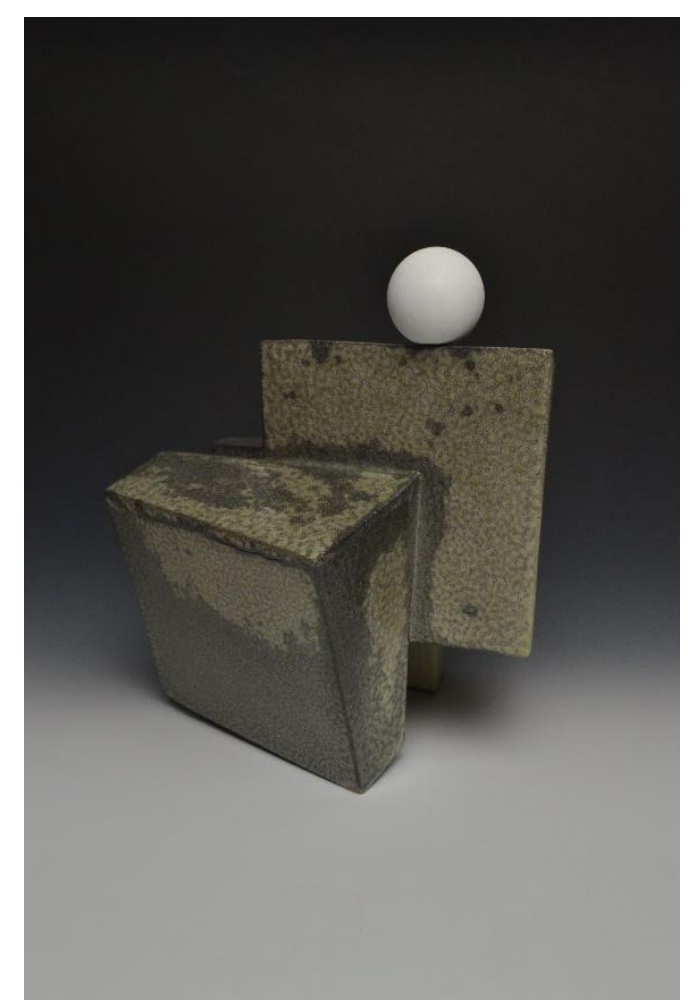

Fig. 5. Ken Lu, Soda Fired, 2017, Stoneware, Soda Fired Cone 10 with acrylic painted ceramic ball, 6 x 9 x 10.5 inches. (Photo courtesy of Ken Lu).

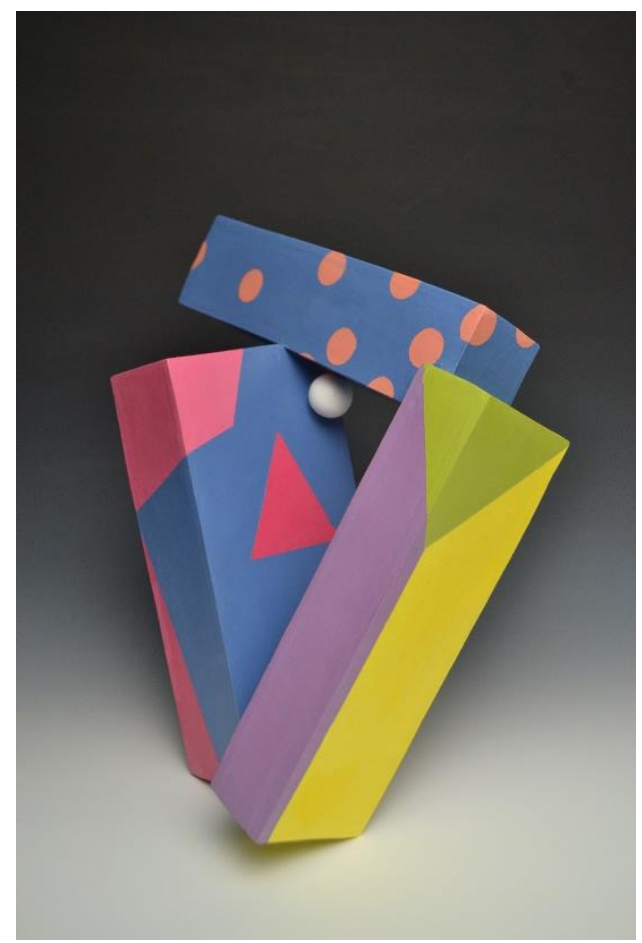

Fig. 6. Ken Lu, Acrylic painted, 2017, Stoneware Oxidation Cone 1 Acrylic painted, 6 x 7.5 x 10 inches. (Photo courtesy of Ken Lu). 


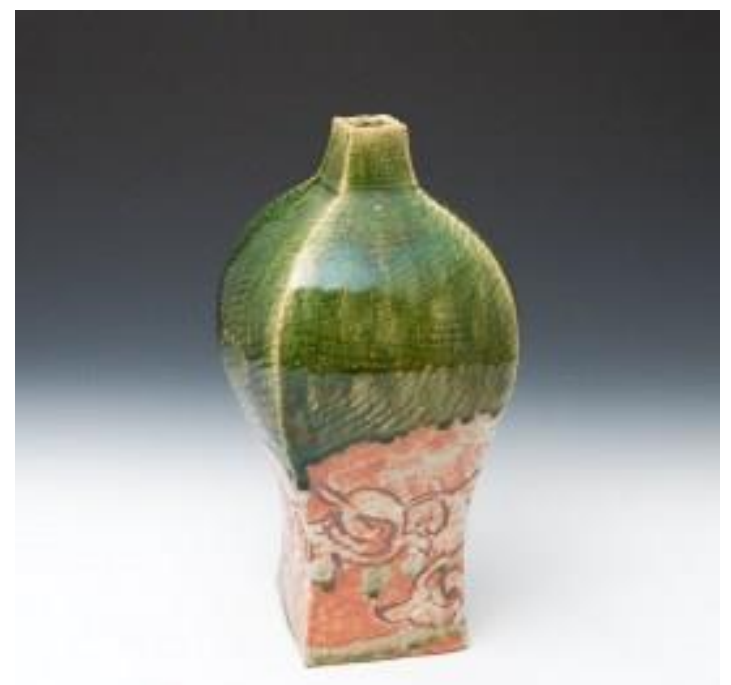

Fig. 7. Ken Matsuzaki, Vase (Narumi Oribe), 2010, Stoneware, 5 x 13 inches. Reproduced from https://www.goldmarkart.com/ceramics/potters/ken-matsuzaki/vase-6775 (accessed April 22, 2018)

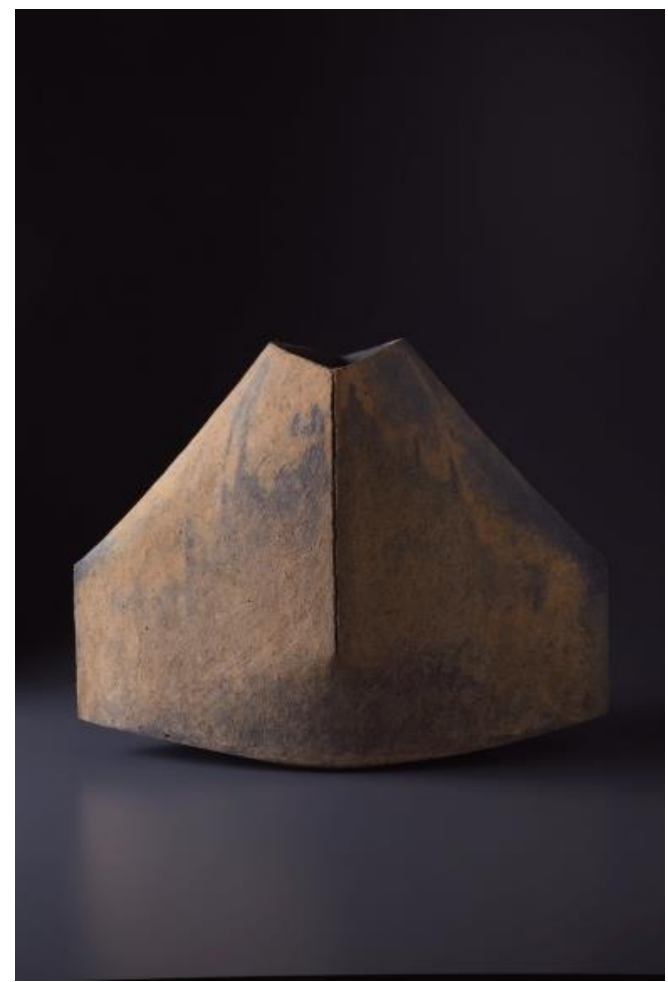

Fig. 8. Ken Mihara, Untitled, 2007, Stoneware Multi-fired with colorants of orange and ash blue, 14 3/4 x 8 1/4 inches. Reproduced from www.mirviss.com/artists/miharaken?view=slider\#3 (accessed April 22, 2018) 

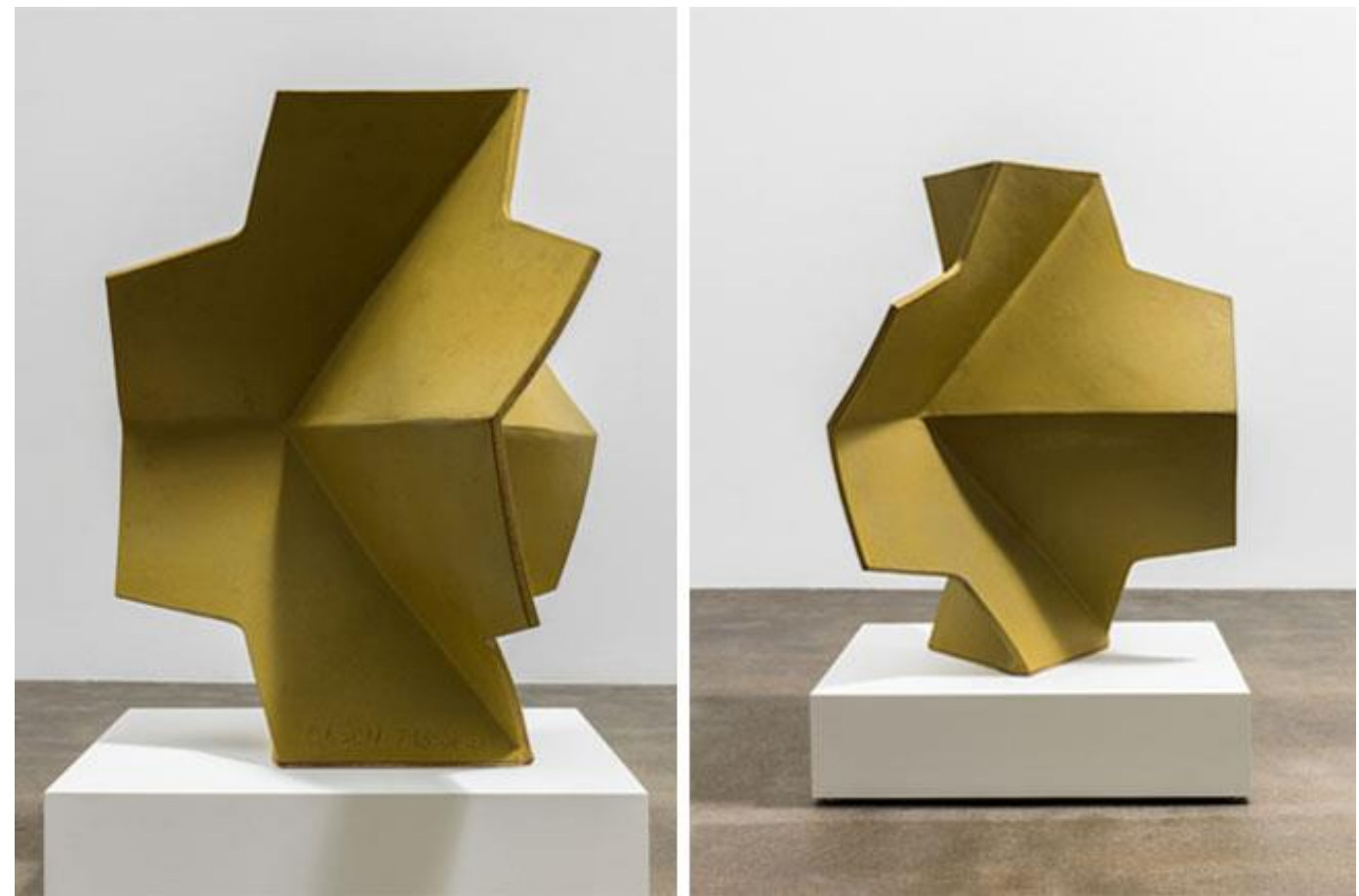

Fig. 9. John Mason, Folded Cross, Yellow-Gold, 2002, Ceramic, 39 x 31.5 x 24 inches. Reproduced from https://cfileonline.org/exhibits-john-mason-david-kordansky-gallery/ (accessed April 22, 2018)

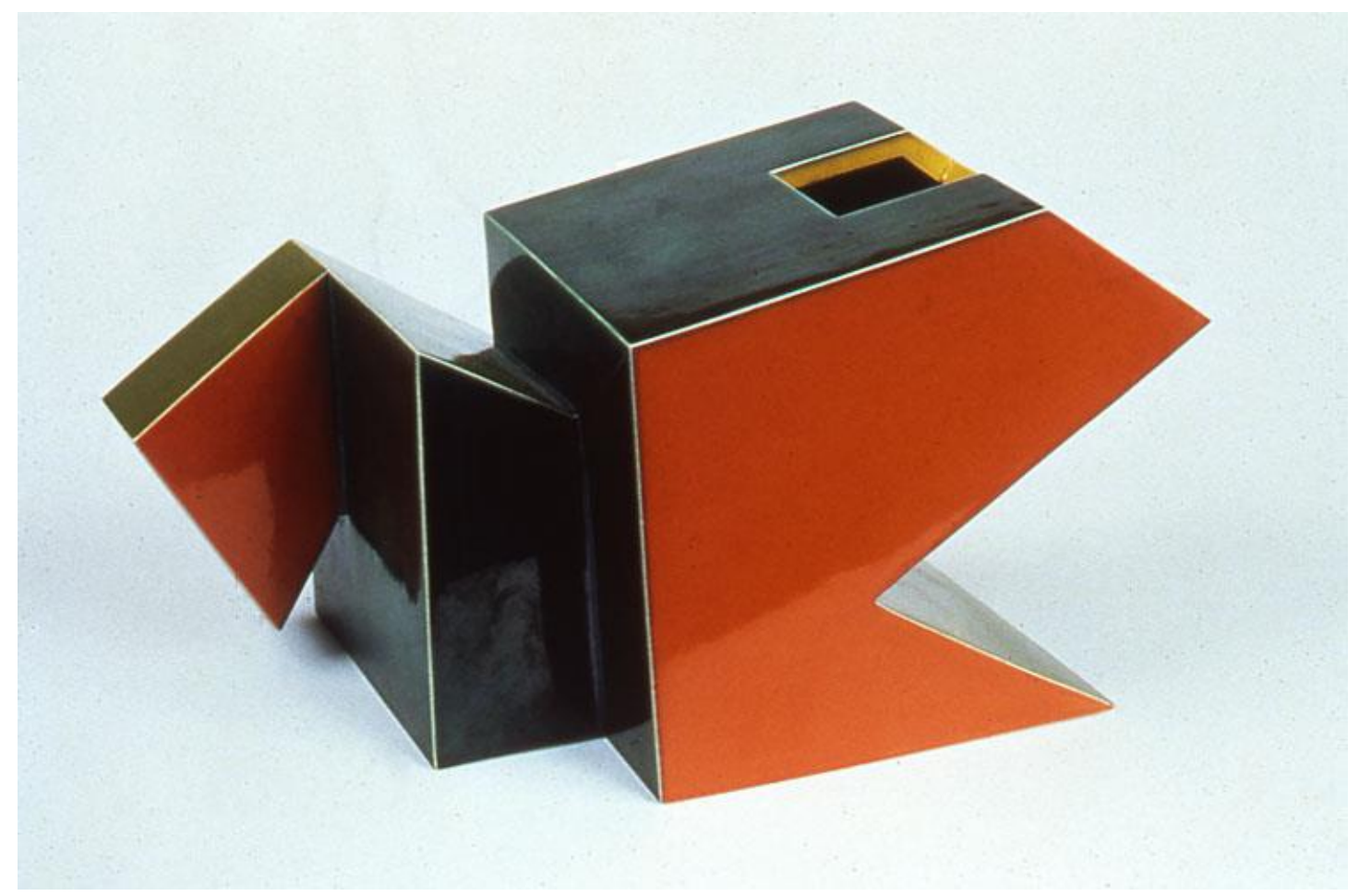

Fig. 10. Ken Price, Untitled, 1980, Ceramic, 6 inches. Reproduced from https://craftcouncil.org/post/remembering-ken-price (accessed April 22, 2018) 


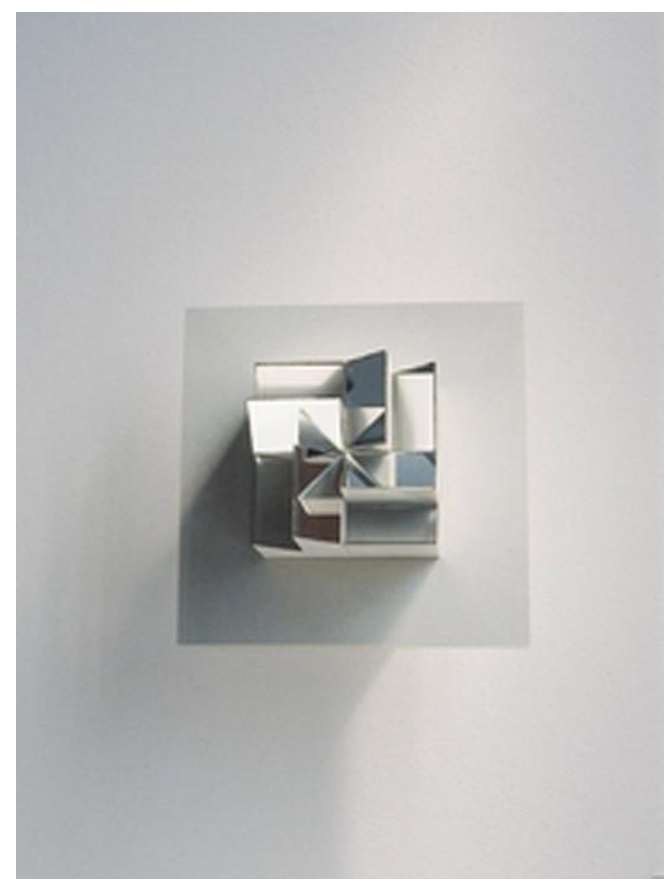

Fig. 11. Kenneth and Mary Martin, Rotation Multiple Not Limited, 1968, Prints and multiples, Injection molded plastic and mirror multiple, 5 x 5 inches. Reproduced from http://www.artnet.com/artists/mary-martin/rotation-mm1-a-ZWye4LHgAY6PGsuSz_CeGw2 (accessed April 5, 2018)

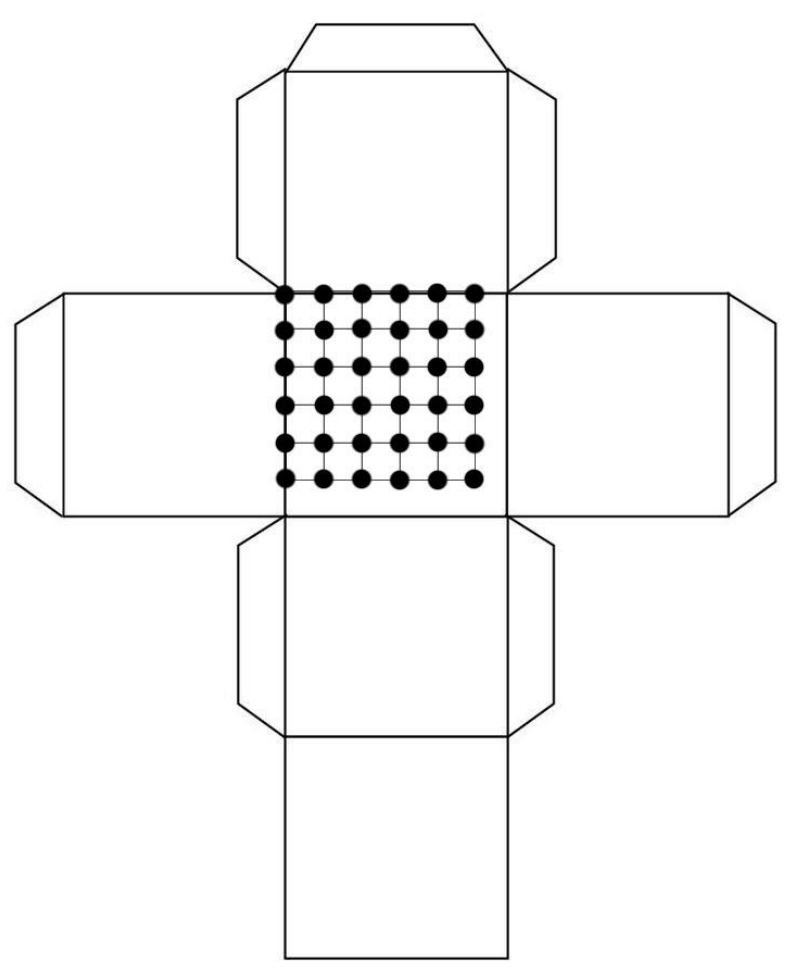

Fig. 12. Ken Lu, 25 Grid points on cube template. (Photo courtesy of Ken Lu) 


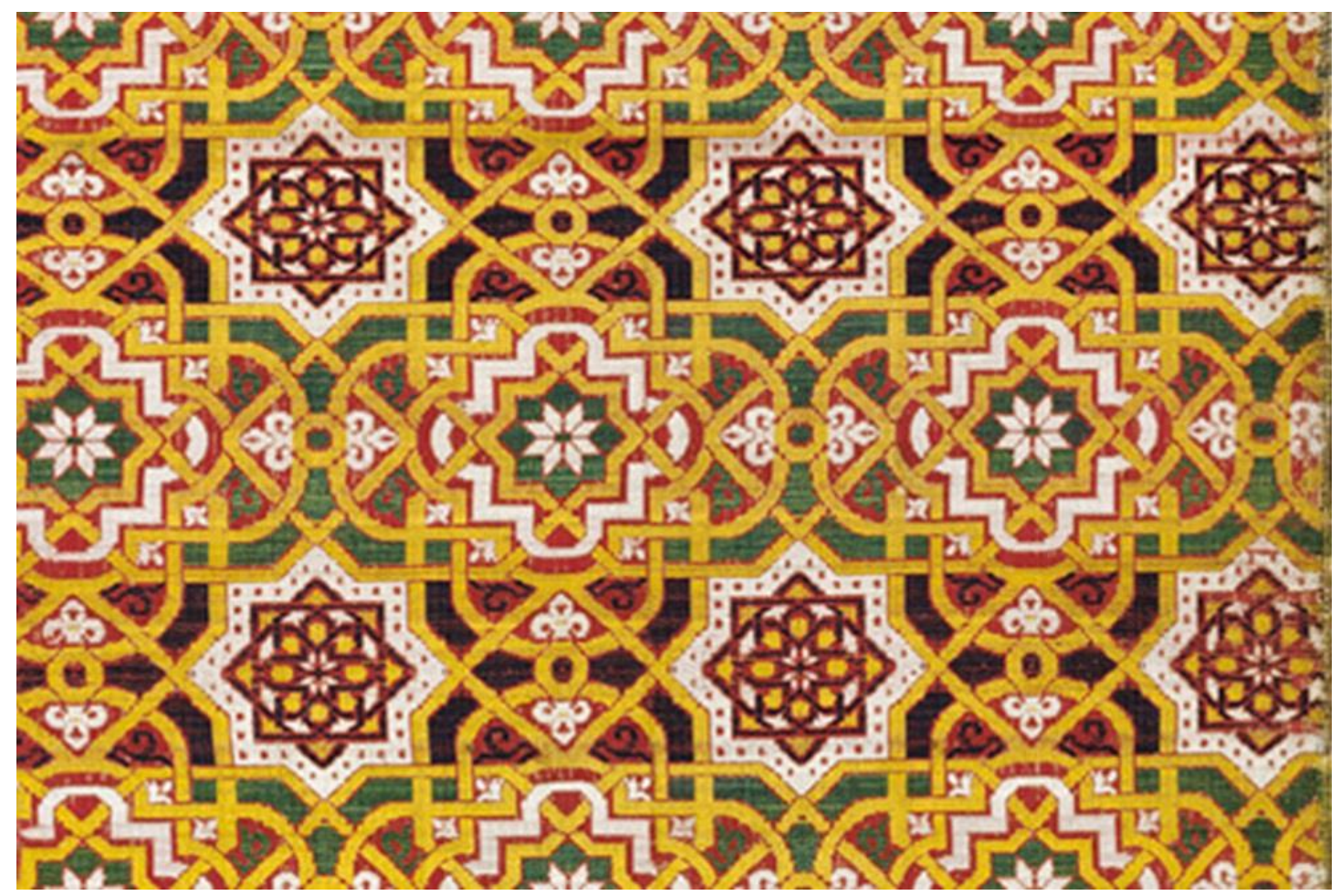

Fig. 13. Islamic Art and Geometric Design (Textile fragment), $14^{\text {th }}$ century, Spain.

Reproduced from https://www.metmuseum.org/learn/educators/curriculum-resources/art-ofthe-islamic-world/unit-three (accessed April 5, 2018)

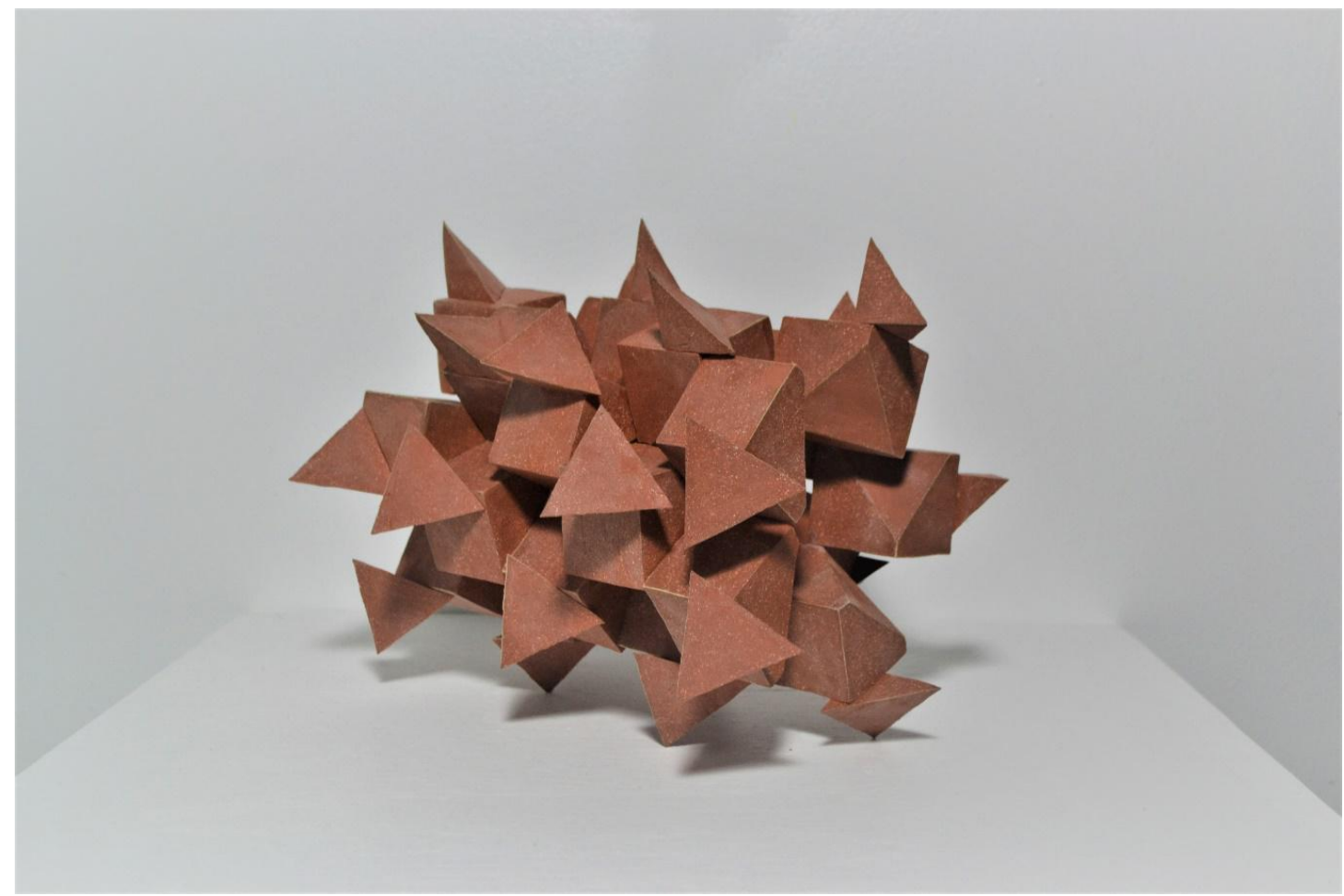

Fig. 14. Ken Lu, Cylinder form, 2018, Stoneware Oxidation Cone 1, 11 x 7.5 x 7.5 inches. (Photo courtesy of Ken Lu). 


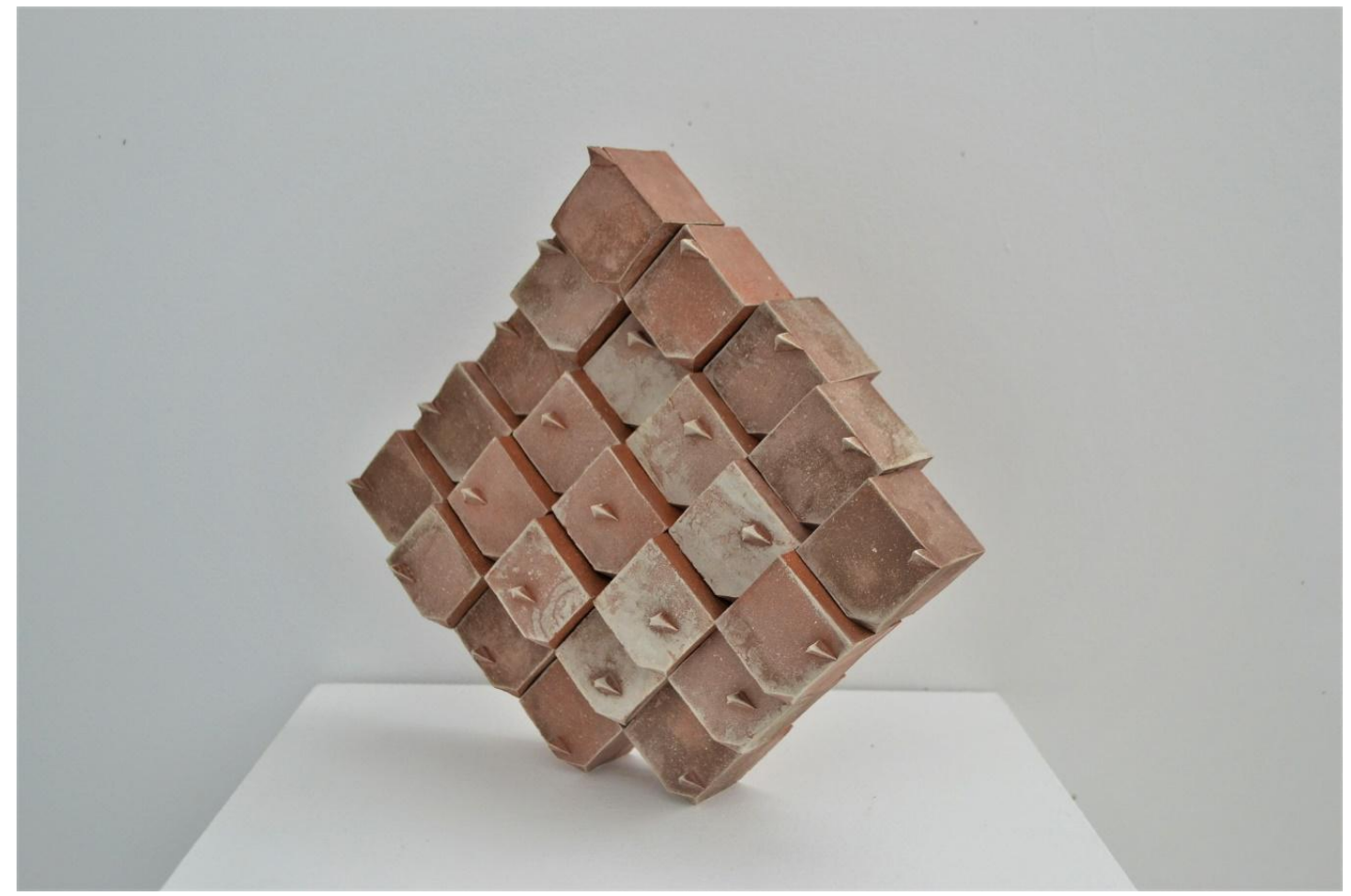

Fig. 15. Ken Lu, Wave form, 2018, Stoneware Oxidation Cone 1, 12.5 x 2.5 x 11.5 inches (Photo courtesy of Ken Lu).

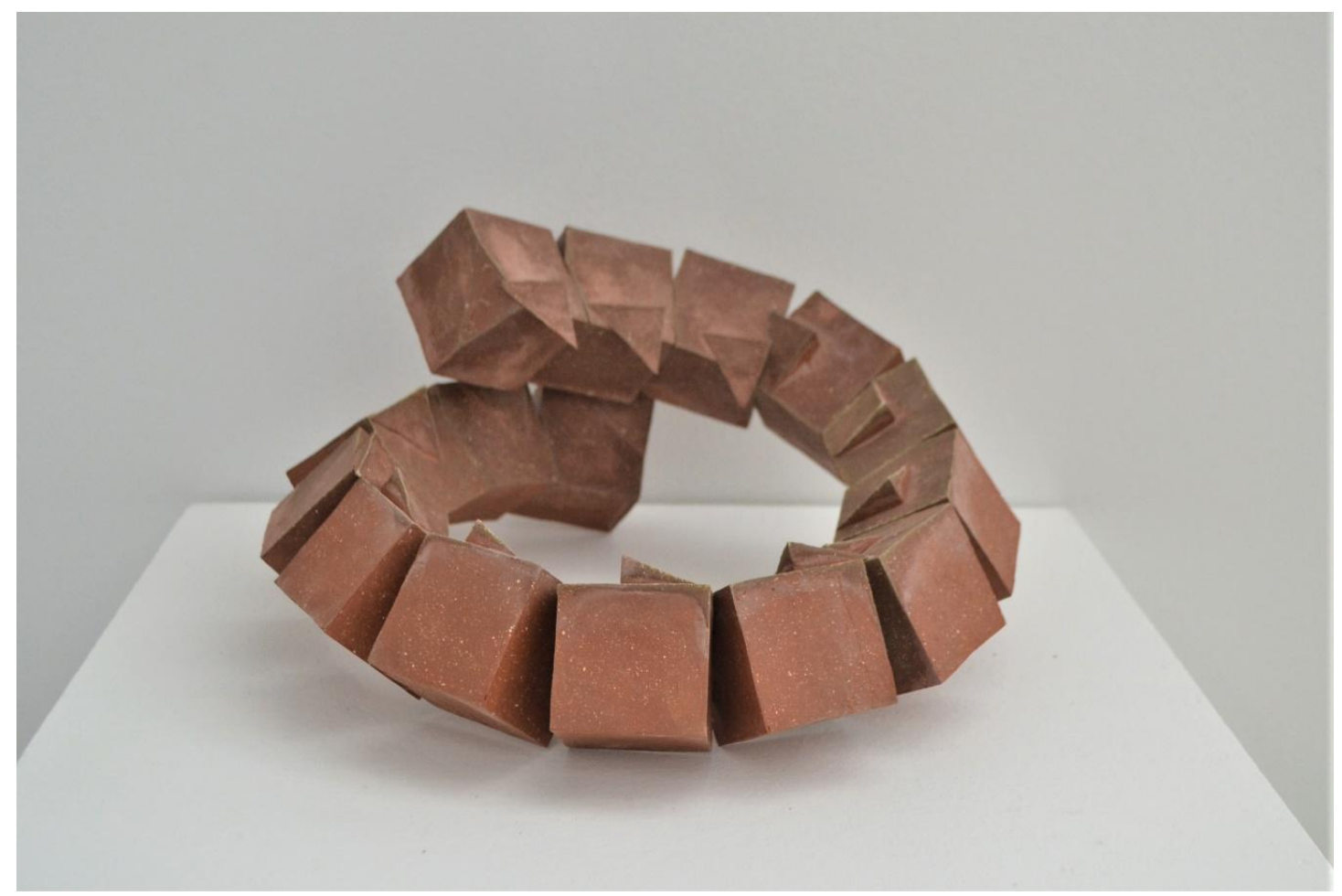

Fig. 16. Ken Lu, Spiral form, 2018, Stoneware Oxidation Cone 1, 10.5 x 10.5 x 5.5 inches. (Photo courtesy of Ken Lu). 


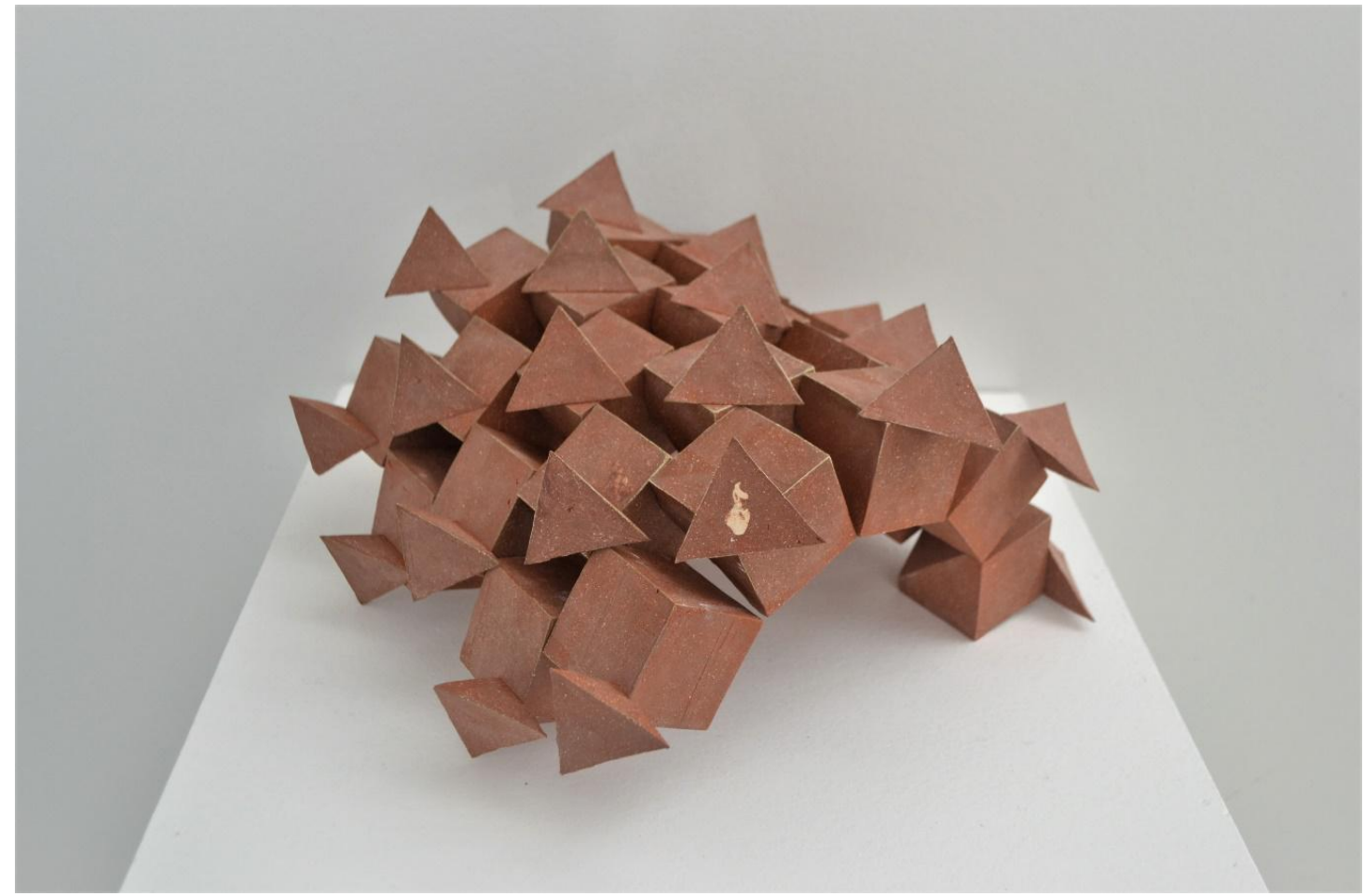

Fig. 17. Ken Lu, Arch form, 2018, Stoneware Oxidation Cone 1, 13 x 11 x 6.5 inches. (Photo courtesy of Ken Lu).

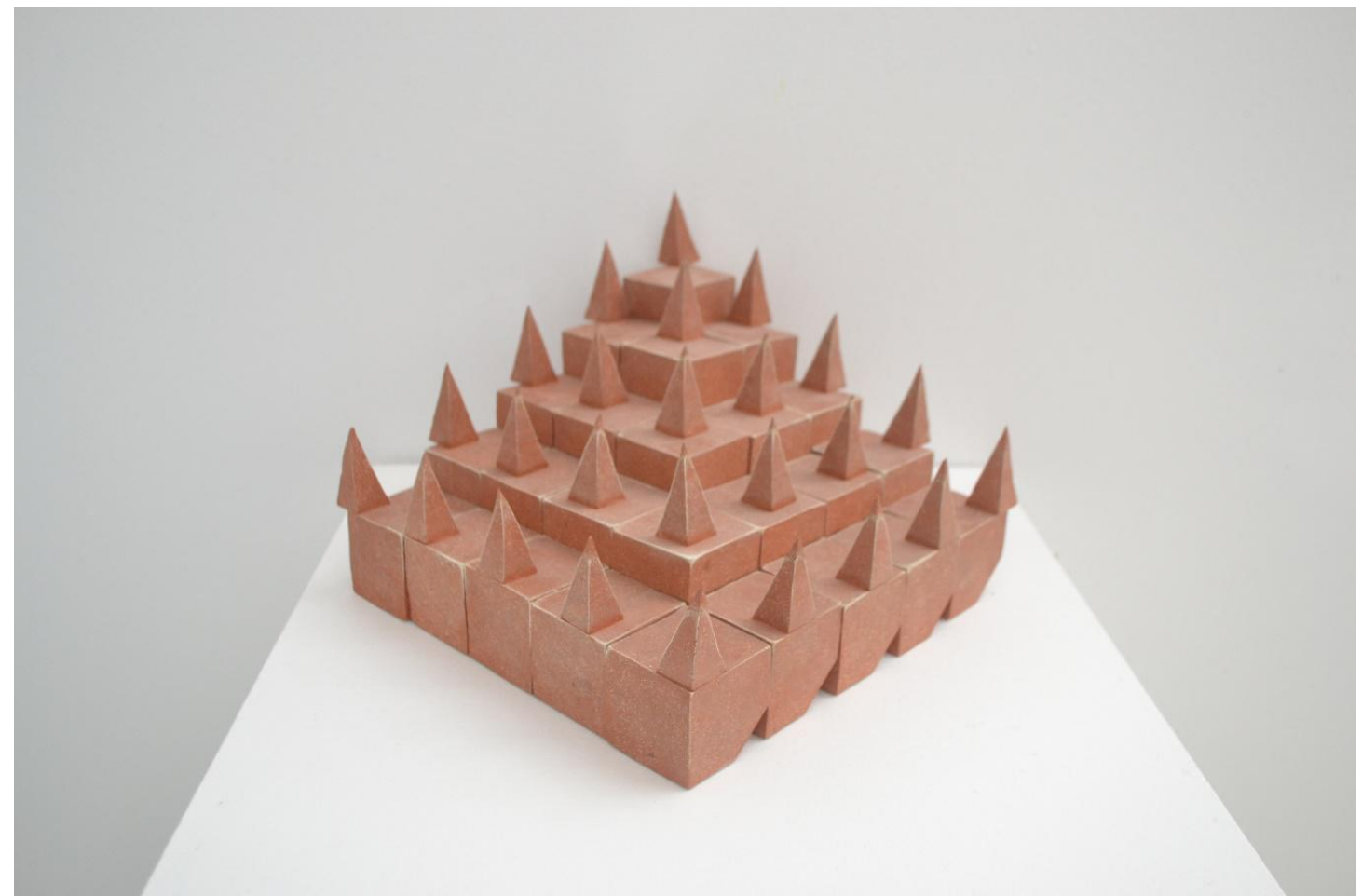

Fig. 18. Ken Lu, Ziggurat form, 2018, Stoneware Oxidation Cone 1, 11.5 x 11.5 x 7 inches. (Photo courtesy of Ken Lu). 


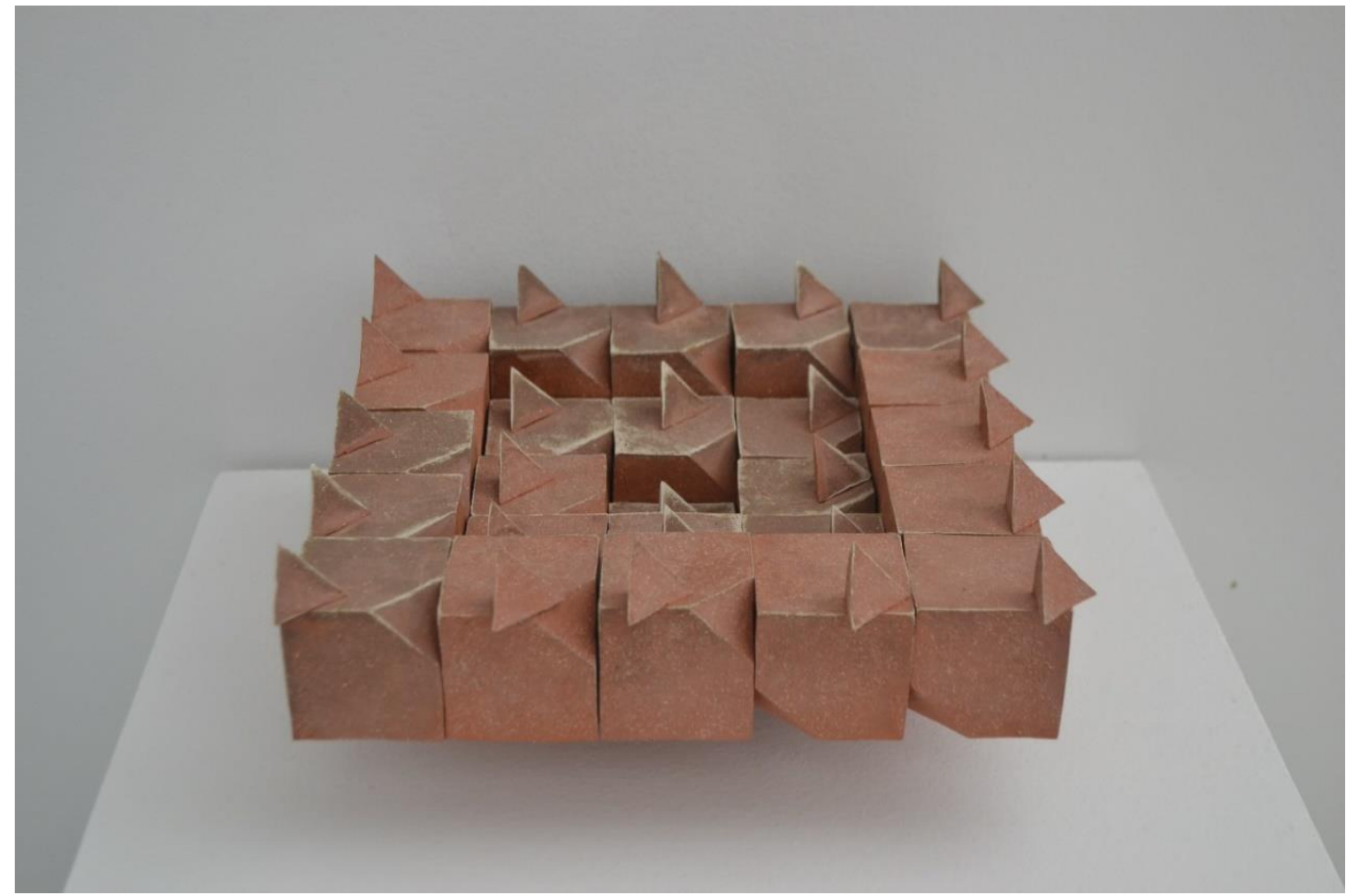

Fig. 19. Ken Lu, Height increment, 2018, Stoneware Oxidation Cone 1, 13 x 11 x 6.5 inches. (Photo courtesy of Ken Lu).

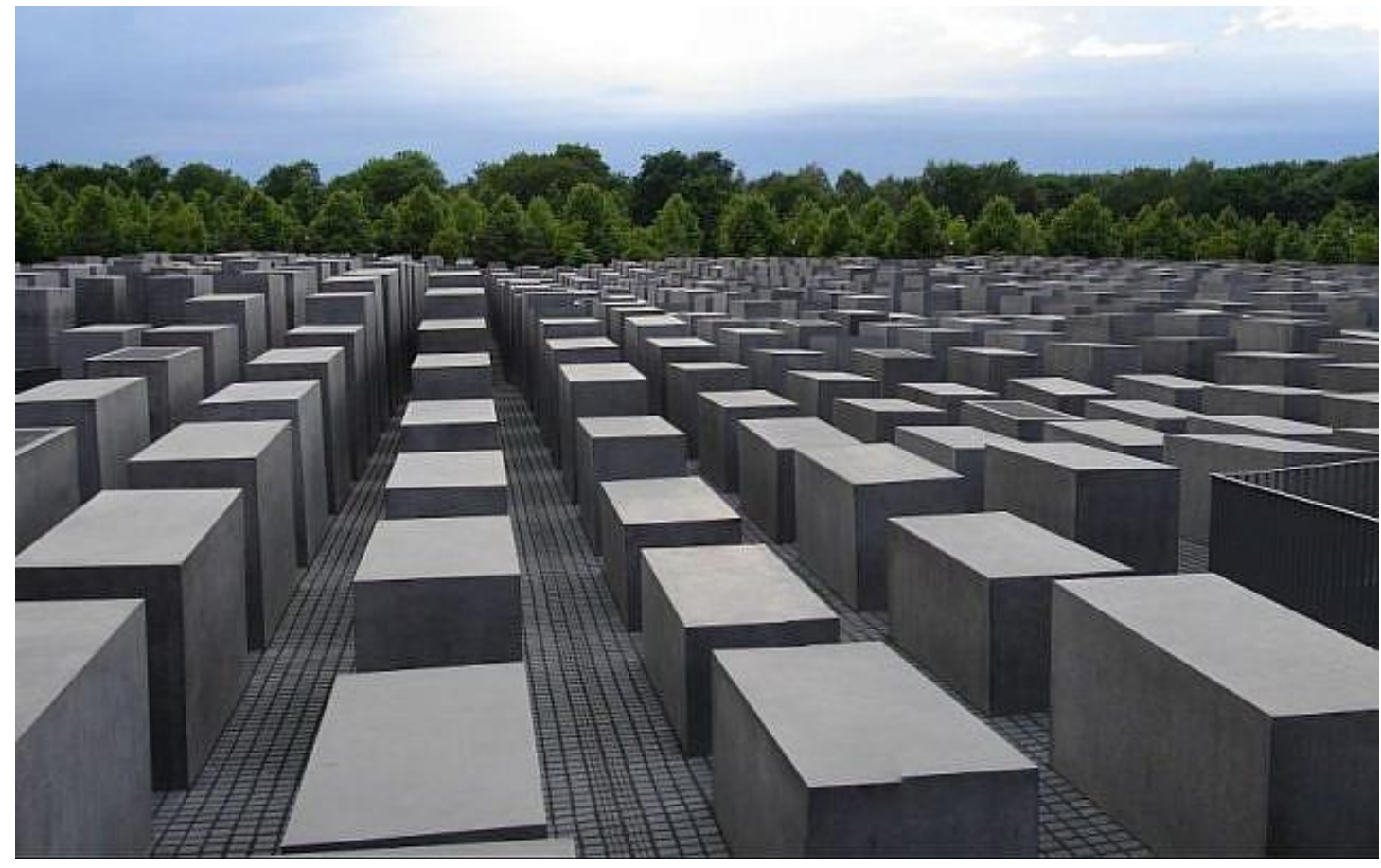

Fig. 20. Peter Eisenman, Memorial to the Murdered Jews of Europe, 2005, Germany.

Reproduced from https://www.timesofisrael.com/german-far-right-wants-place-on-board-ofberlins-national-holocaust-memorial/ (accessed April 5, 2018). 


\section{Bibliography}

Bolton, Ruth N., A. Parasuraman, Ankie Hoefnagels, Nanne Migchels, Sertan Kabadayi, Thorsten Gruber, Yuliya Komarova Loureiro, David Solnet. Understanding Generation $Y$ and their use of social media: a review and research agenda"Journal of Service Management, Vol. 24 Issue: 3 (2013), pp.245-267, accessed: March 7, 2018. https://doi.org/10.1108/09564231311326987

Bursill-Hall, Piers. "Why do we study geometry? Answers through the ages." DPMMS Centre for Mathematical Sciences Wilberforce Road, Cambridge (2002): 1-31.

Craven, Jackie. "About the 2005 Berlin Holocaust Memorial” last modified March 24, 2018. https://www.thoughtco.com/the-berlin-holocaust-memorial-by-peter-eisenman-177928

Duan, Ruoyu. "Individualism in America." Faculty of English Language and Culture Guangdong University of Foreign Studies. November 2014.

Fausset, Richard and Serge F, Kovaleski. "Nikolas Cruz, Florida Shooting Suspect, Showed 'Every Red Flag”'. The New York Times. Feb 15, 2018. Accessed: March 1, 2018. https://www.nytimes.com/2018/02/15/us/nikolas-cruz-florida-shooting

Guattari, Pierre-Felix. The Guattari Reader, Edited by Gary Genosko. Blackwell Publishers. 1996.

Harrison, Charles, and Paul Wood. Art in Theory, 1900-2000: An Anthology of Changing Ideas. 2nd Ed. ed. Malden, MA: Blackwell Pub, 2003.

Higgins, Hannah. The Grid Book. Cambridge, Mass.: MIT Press, 2009.

Islamic Art and Geometric Design. The Metropolitan Museum of Art, New York, 2004. Accessed: April 4, 2018.

https://www.metmuseum.org/ /media/Files/Learn/For\%20Educators/Publications\%20for \%20Educators/Islamic_Art_and_Geometric_Design.pdf

Kaplan, Isaac. “How Long Do People Really Spend Looking at Art in Museums?”. Last modified November 7, 2017. https://www.artsy.net/article/artsy-editorial-long-peoplespend-art-museumsMeyer, James Lawlor, Robert. Sacred Geometry: Philosophy and Practice. Thames \& Hudson, 1982.

Lowe, Peter, Edward Grabczewski. The Systems Art of Peter Lowe (2008). Video. 48.31. Sep

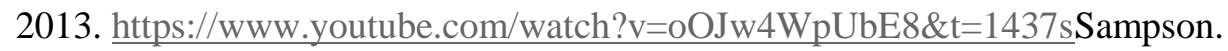

Minimalism. London: Phaidon, 2000. 
Morgan, Robert C. "Sol LeWitt: Systemic Art Made Visual," Sculpture 21, no. 5 (June 2002): 30-35. Art Abstracts (H.W. Wilson), EBSCOhost (accessed November 18, 2017).

Strickland, Edward. Minimalism: Origins. Bloomington: Indiana University Press, 1993.

Morris, Robert. "Notes on Sculpture". Artforum. October 1966. Accessed: March 7, 2018. http://arts.berkeley.edu/wp-content/uploads/2016/01/robert-morris-notes.pdf

Reb, Michael. Analysis of Variation of Incomplete Open Cubes by Sol LeWitt. Kansas State University, 2013. 


\section{Lu Yong Jian Ken}

Masters of Fine Arts Candidate in Ceramics

West Virginia University

1 Fine Arts Drive, Morgantown, WV 26505

Cellphone: 304.777.7198 Email: kylu@mix.wvu.edu

\section{EDUCATION}

\begin{tabular}{ll}
\hline 2015-18 & $\begin{array}{c}\text { Masters of Fine Arts Candidate in Ceramics } \\
\text { West Virginia University, Morgantown, WV, USA } \\
\text { 2011-15 } \\
\text { Bachelor of Fine Arts in Ceramics } \\
\text { Jingdezhen Ceramics Institute Department of Arts and Design } \\
\text { Jingdezhen, Jiangxi Province, China }\end{array}$
\end{tabular}

\section{PROFESSIONAL AND RELATED EXPERIENCE}

2018 Instructor on record, West Virginia University, Morgantown, WV, USA Visual Foundations (3 Dimensional)

2017 Summer Studio Staff, Watershed Center for the Ceramic Arts, Newcastle, ME, USA

Instructor on record, West Virginia University, Morgantown, WV, USA Teaches wheel-throwing, pinching, and slab-building to non-majors and Drawing to majors

2016 Summer Program at Chautauqua School of Art, Chautauqua, NY, USA Instructor on record, West Virginia University, Morgantown, WV, USA Teaches wheel-throwing, pinching, and slab-building to non-majors.

2013-15 Co-owner of JuWaiRen Cafe, Jingdezhen, JiangXi Province, China Made all serving wares and sold wares off shop.

2014-15 Wheel Throwing Assistant, Jingdezhen, Jiangxi Province, China Studio assistant for Alexandra Copeland

2013-15 Wheel-throwing Teacher, Kungfu Mud), Jingdezhen, Jiangxi Province, China Taught 1 Week Beginner and Intermediate Class Workshops

2012-15 Volunteer, Pottery Workshop Education Center, Jingdezhen, Jiangxi Province, China Assisting the staff daily and Exchange Programs

2012- 14 Kindergarten Teacher, ChangHe Kindergarten, Jingdezhen, Jiangxi Province, China Taught English language to 3-6-year-old children. Introduction of new syllabus

2010-11 $\quad 3^{\text {rd }}$ Sergeant (Operational Unit) Explosive Ordnance Disposal Unit, Singapore Arm Forces, Singapore

\section{FELLOWSHIPS/SCHOLARSHIPS/AWARDS}

2017

Graduate Teaching Assistantship, West Virginia University, Morgantown, WV, USA

Dwight M. Holland Scholarship, Randolph Arts Guild, Asheboro, NC, USA

Windgate Scholarship, Anderson Ranch Arts Center, Snowmass Village, CO, USA

Graduate Teaching Assistant-ship, West Virginia University, Morgantown, WV, USA

Chautauqua Studio Scholarship, 3800USD, Chautauqua, NY, USA

GPS Travel Grant, 500USD, West Virginia University, Morgantown, WV, USA

School of Art and Design Scholarship, 500USD, West Virginia University, Morgantown, WV, USA

2015 One Year Provost Fellowship, tuition waived plus 17000USD stipend, West Virginia University, Morgantown, WV, USA University Wide Merit Base Fellowship 
Canady Scholarship, 1000USD, West Virginia University, Morgantown, WV, USA

\section{EXIHIBITIONS}

Based on Academic Credentials and bilingual

2018

2017

2016

2015

2014-

\section{KILN BUILDING EXPERIENCE}

$2015 \quad 0.5$ cubic meter Train Kiln (Assistant), With Lindsay Oesterritter and Ted Neal

2014

2014

2014

Virginia University, Morgantown, WV, USA

University Shipping Containers Shows, Standard Ceramics, Carnegie, PA, USA

Confluence Show 2018, Artist Image Resource, Pittsburgh, PA, USA

The Cup, The Mug, Main Street Gallery, Roschester, NY, USA

Juried Student Exhibition 2017, Mesaros Gallery, West Virginia University, Morgantown, WV, USA

Two Man Show, Solo show at The Diamond Shop which includes ceramics and painting, Morgantown, WV, USA

Almighty Cups, Juror: Liz Lurie, Gandee Gallery, Fabius, NY, USA

Summer Exhibition at Evansdale and Downtown Library, WVU Clay Club, WVU, Morgantown, WV, USA

$13^{\text {th }}$ Annual Art Kudos International Exhibition, Online Juried Competition

Vessels: Interpretation and Iterations, Juror: Bill Wilkey, Kentucky Mudworks, Louisville, Kentucky, USA

SIP- A Ceramic Cup Show, Juror: Kimberly Riner, Savannah Clay Community, Savannah, GA, USA

Twin Cups, Juror: Ted Neal, MWSU, Saint Joseph, MO, USA

Teapot VIII, Juror: Sam Chung, Baltimore Clayworks, Baltimore, MD, USA

The Cup, The Mug, Juror: Peter Pincus, Main Street Gallery, Roschester, NY, USA

Almighty Cups, Juror: David Macdonald, Gandee Gallery, Fabius, NY, USA

Function, Clay Club Exhibition, Diamond Art Gallery, Morgantown, WV, USA

Student Exhibition, Juror: Don Kimes, Fowler Kellog Gallery, Chautauqua, NY, USA

Confluence Show 2016, Artist Image Resource, Pittsburgh, PA, USA

Surrounding: MFA students Respond to their Environment(s) Laura Mesaros Gallery, West Virginia University, Morgantown, WV, USA

Working Pots Exhibition, Juror: Simon Levin, James May Gallery, Agoma, WI, USA

Tamarack: The Best of West Virginia, David L. Dickirson Fine Arts Gallery, Beckley, WV, USA

Proximity, Juror: John Landers, The Clay Co-Ops, Rockville, MD, USA

Juried Exhibition, Juror: Joseph Lupo, Side Street Gallery, Morgantown,

WV, USA

Juried Student Exhibition 2016, Juror: Jason Lee, West Virginia University, Morgantown, WV, USA

Kungfu Mud Studio, Invitation, Wuhan, Hubei Province, China Permanent display of Mini Sculptural Kiln

$$
\text { Manassas, VA, USA }
$$

1 cubic meter Smokeless Cross-draft wood kiln (Assistant), Nine Burn Studio Jingdezhen, Jiangxi Province, China

0.25 cubic meter Wood/Soda Tube Kiln (Design), Nine Burn Studio Jingdezhen, Jiangxi Province, China

1 cubic meter Smokeless Cross-draft wood kiln(Coordinator), Wangshan

Studio

Nanjing, Jiangsu Province, China 


\section{DEMONSTRATIONS/WORKSHOPS}

2017 The Structure of Pots, Instructor: Dan Murphy, Anderson Ranch Arts

Center, Snowmass, CO, USA

2016 Bloom!, Blossom's Arts Center, Frederick, NY, USA Invited Artist to demonstrate altering wheel-thrown forms

20144 Day Wheel Throwing Workshop (Instructor) Organized by Kungfu Mud JianShui Art Institute, Jianshui, Yunnan Province, China

2012, 14 October Festival. Pottery Workshop, Jingdezhen, Jiangxi Province, China Built and fired Mini Sculptural Kilns

\section{RELATED ACTIVITIES}

2017

2016

Treasurer for WVU Clay Club, Morgantown, WV, USA

Vice- President for WVU Clay Club, Morgantown, WV, USA

Treasurer for WVU Clay Club, Morgantown, WV, USA

Vice- President for WVU Clay Club, Morgantown, WV, USA

Facilitator for Pinch Bowl, Morgantown, WV, USA Bowls made are donated to Empty Bowls

Presidential Farewell Party, Chautauqua, NY, USA Wheel throwing during a speech

$2014 \quad$ Friday Night Lecture Series: Guest Lecturer Pottery Workshop, Jingdezhen, Jiangxi Province, China

2013 Wheel Thrower role, Beijing, Hebei Province, China Audition for Chinese New Year Eve Celebration on Television Guest Lecturer, Jianghan University, Wuhan, Hubei Province, China

\section{Conference Membership}

2018 NCECA- Volunteer, Pittsburgh, PA, USA

2017 NCECA- Volunteer, Portland, OR, USA

North Carolina Potter's Conference- Attendee, Asheboro, NC, USA

2016

NCECA- Volunteer, Kansas City, MO, USA

2014 NCECA- Attendee, Milwaukee, WI, USA

Jingdezhen Ceramic Fair, Attendee, Jingdezhen, Jiangxi Province, China

2012 Jingdezhen Ceramic Fair, Attendee, Jingdezhen, Jiangxi Province, China

\section{Academic Membership}

2016

The Honor Society of Phi Kappa Phi

Nation's oldest and most selective multidisciplinary collegiate honor society

2015

Golden Key International Honour Society

Invitation to top $15 \%$ students in all fields of study base on academic

achievements

\section{Private Collections}

Dwight M. Holland, Asheboro, NC, USA

Reference: Shoji Satake Associate Professor, Coordinator of Ceramics

Shoji.satake@mail.wvu.edu

304-680-7500 